\title{
Morphological characterisation of ventricular septal defects associated with coarctation of aorta by cross-sectional echocardiography
}

\author{
JEFFREY F SMALLHORN^, ROBERT H ANDERSON, FERGUS J MACARTNEY \\ From the Thoracic Unit, The Hospital for Sick Children, Great Ormond Street, London
}

SUMMARY Cross-sectional echocardiograms of 18 neonates and infants with coarctation of the aorta and ventricular septal defect were retrospectively assessed. With a combination of subcostal and precordial cuts the site and anatomical relations of the defects were determined. In one case there was a muscular trabecular ventricular septal defect. Three had a malalignment defect with associated left ventricular outflow tract obstruction. In two there was a doubly committed subarterial defect with associated malalignment of the point of continuity between the aortic and pulmonary valves and the crest of the trabecular septum. Twelve cases had a perimembranous defect, with varying degrees of extension into the inlet, trabecular, or outlet septum. In this group 10 had associated aortic override, with varying degrees of left ventricular outflow tract narrowing. Abnormal insertion of the tricuspid valve was observed in 10 cases, such that it partly obscured the ventricular septal defect.

Thus in most cases of coarctation with ventricular septal defect, the morphology of the ventricular septal defect and ventricular outflow tracts is such that left ventricular ejection is directed towards the pulmonary artery rather than the aorta.

In a recent study on cross-sectional echocardiography in aortic interruption ${ }^{1}$ it was confirmed, as has previously been described from anatomical studies, ${ }^{2-4}$ that the ventricular septal defect is situated such that left ventricular blood preferentially ejects into the pulmonary artery. In the majority of cases this was the result of posterior deviation of the outlet (infundibular) septum into the left ventricular outflow tract.

In a further study on the cross-sectional echocardiographic features of coarctation of the aorta in the sick neonate and infant, it was also observed that in some with a ventricular septal defect there was associated aortic override or posterior infundibular displacement. ${ }^{5}$ A recent morphological study by Anderson, Lenox, and Zuberbuhler ${ }^{6}$ of the specimens in the cardiopathological collection of The Children's Hospital of Pittsburgh, with ventricular septal defect

^Present address: Department of Pediatric Cardiology, The Hospital for Sick Children, 555 University Avenue, Toronto, Ontario, Canada.

FJM and RHA are supported by the British Heart Foundation and, respectively, the Vandervell and Joseph Levy Foundations.

Accepted for publication 15 February 1983 associated with aortic coarctation, showed that aortic override or posterior displacement of the outlet septum was a common association, occurring in 24 out of 25 hearts studied. As it is likely that a necropsy study does not present a true picture of the spectrum seen in clinical practice, we investigated in more detail the cross-sectional echocardiographic findings of those patients who had presented over the past two years in The Hospital for Sick Children, London, with a diagnosis of coarctation of the aorta and ventricular septal defect.

\section{Subjects and methods}

The cross-sectional echocardiograms were examined retrospectively and the results correlated with available angiocardiographic or necropsy material. Only those cases with atrioventricular and ventriculoarterial concordance and "normal relations" were included in the study. During the examination the level of atrioventricular valves and the status of the muscular septum were assessed in a subcostal and apical long axis cut at right angles to the inlet septum ("four chamber"). Then with clockwise rotation of the 
Table Associated anomalies seen with coarctation and ventricular septal defect

\begin{tabular}{lllll}
\hline Ventricular septal defect & No. cases & Aortic override & LVOTO & Abnormal TV \\
\hline Doubly committed subarterial & 2 & - & 2 & - \\
Malalignment & 3 & - & 3 & - \\
Muscular trabecular & 1 & 2 & 1 & 1 \\
Perimembranous trabecular & 4 & 4 & 3 \\
Perimembranous trabecular + outlet & 4 & 4 & 1 & 2 \\
Perimembranous trabecular + outlet + inlet & 4 & 4 & \\
\hline
\end{tabular}

LVOTO, left ventricular outflow tract obstruction; TV, tricuspid valve.

transducer the left ventricular outflow tract and perimembranous region were inspected. With further clockwise rotation the morphology of the outlet septum was assessed. Next a precordial long axis cut was performed at right angles to the outlet septum and with clockwise rotation of the transducer the right ventricular outflow tract could be seen. The presence of an overriding aortic valve was only assessed in the precordial long axis cut. Finally a precordial short axis cut at the level of the papillary muscles was obtained, and the transducer then directed so as to scan the left ventricular outflow tract. With these combined manoeuvres the presence and site of a ventricular septal defect could be determined, provided it fell within the range of axial and lateral resolution.
In one patient who died the specimen was examined and tomographic sections obtained.

\section{Results}

Eighteen cases were judged to have a ventricular septal defect by cross-sectional echocardiography. The defect was considered large in 15, medium sized in one, and small in two. Angiocardiographic or necropsy confirmation was available in all of those with a significant ventricular septal defect. A summary of the echocardiographic findings is shown in the Table. One case had posterior muscular trabecular ventricular septal defect which was plugged by tricuspid valve

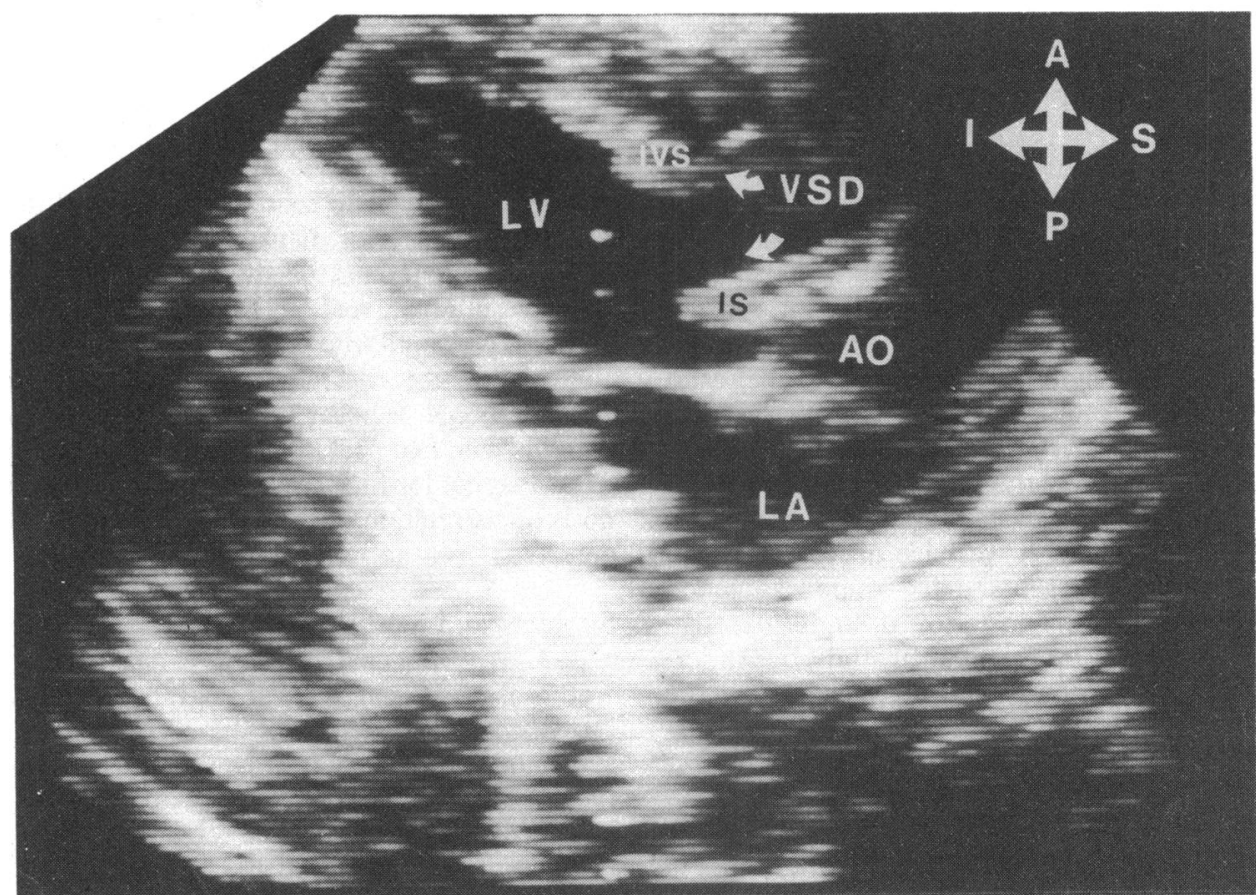

Fig. 1 Precordial long axis cut in coarctation and malalignment ventricular septal defect. Note the ventricular septal defect and the infundibular septum which is displaced posteriorly in to the left ventricular outflow tract. $A O$, aorta; IVS, interventricular septum; LA, left atrium, $L V$, left ventricle, VSD, ventricular septal defect; IS, infundibular septum. 


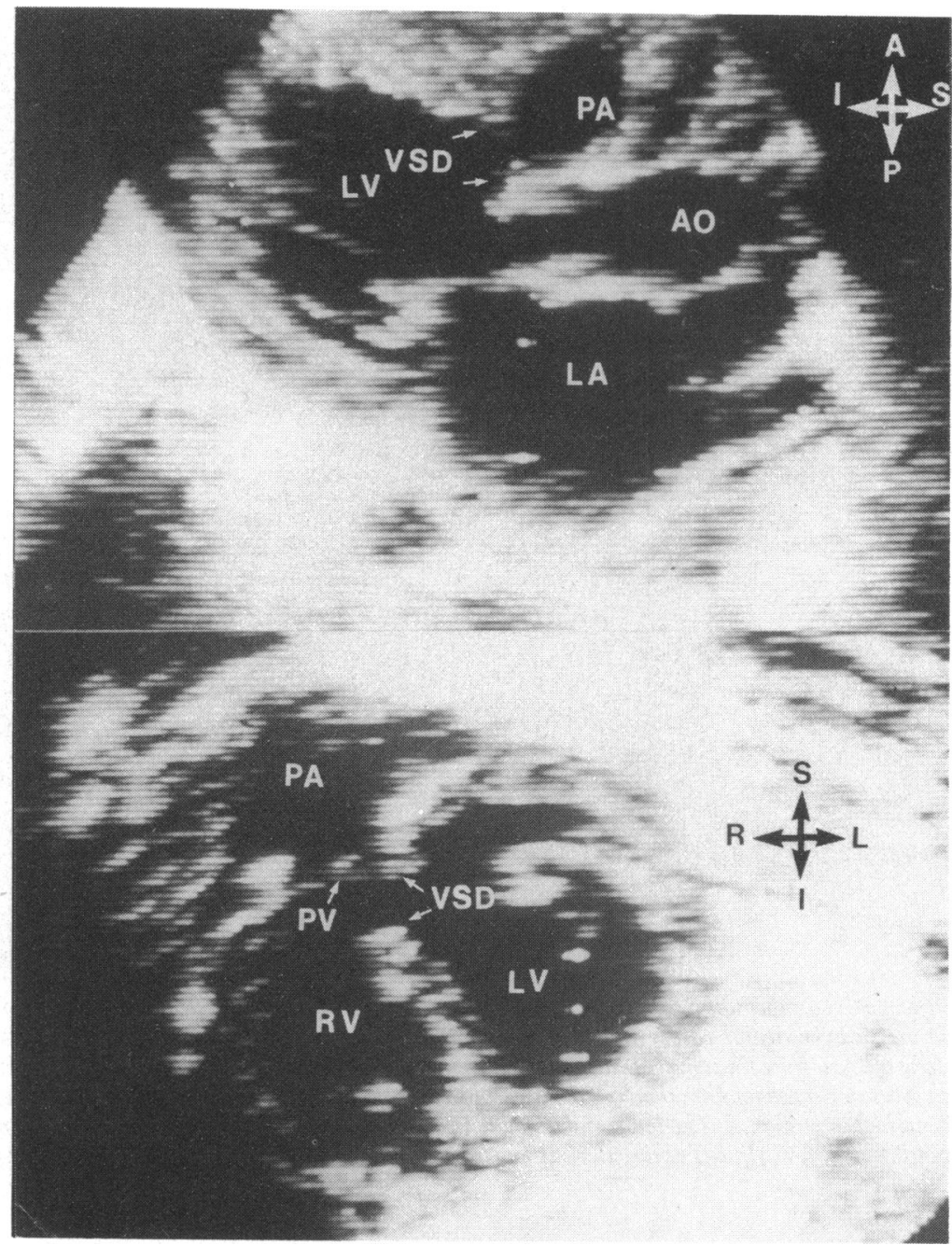

Fig. 2 The upper picture is a precordial long axis cut in a doubly committed subarterial ventricular septal defect. Note the malalignment between the point of continuity between the aortic and pulmonary valves and the crest of the trabecular septum. The lower picture is a subcostal short axis cut from the same case. Note the ventricular septal defect is roofed by the pulmonary valve. $P A$, pulmonary artery; $P V$, pulmonary valve; $R V$, right ventricle. For the rest of the abbreviations see Fig. 1.

tissue during systole. Three had a malalignment ventricular septal defect, with posterior displacement of the outlet septum in the left ventricular outflow tract (Fig. 1). Two cases had a doubly committed subarterial ventricular septal defect without extension back towards the membranous septum (Fig. 2). In both of these the point of continuity between the aortic and pulmonary valves was displaced relative to the crest of the trabecular septum, again resulting in malalign- ment and the substrate for preferential flow from left ventricle to pulmonary artery (Fig. 2).

Four cases had a perimembranous trabecular ventricular septal defect, two of whom had associated aortic override (Fig. 3). In one the left ventricular outflow tract appeared narrow (Fig. 3). Four cases had a perimembranous defect which excavated both the trabecular and outlet septum (Fig. 4). In one there was an associated low trabecular ventricular septal 


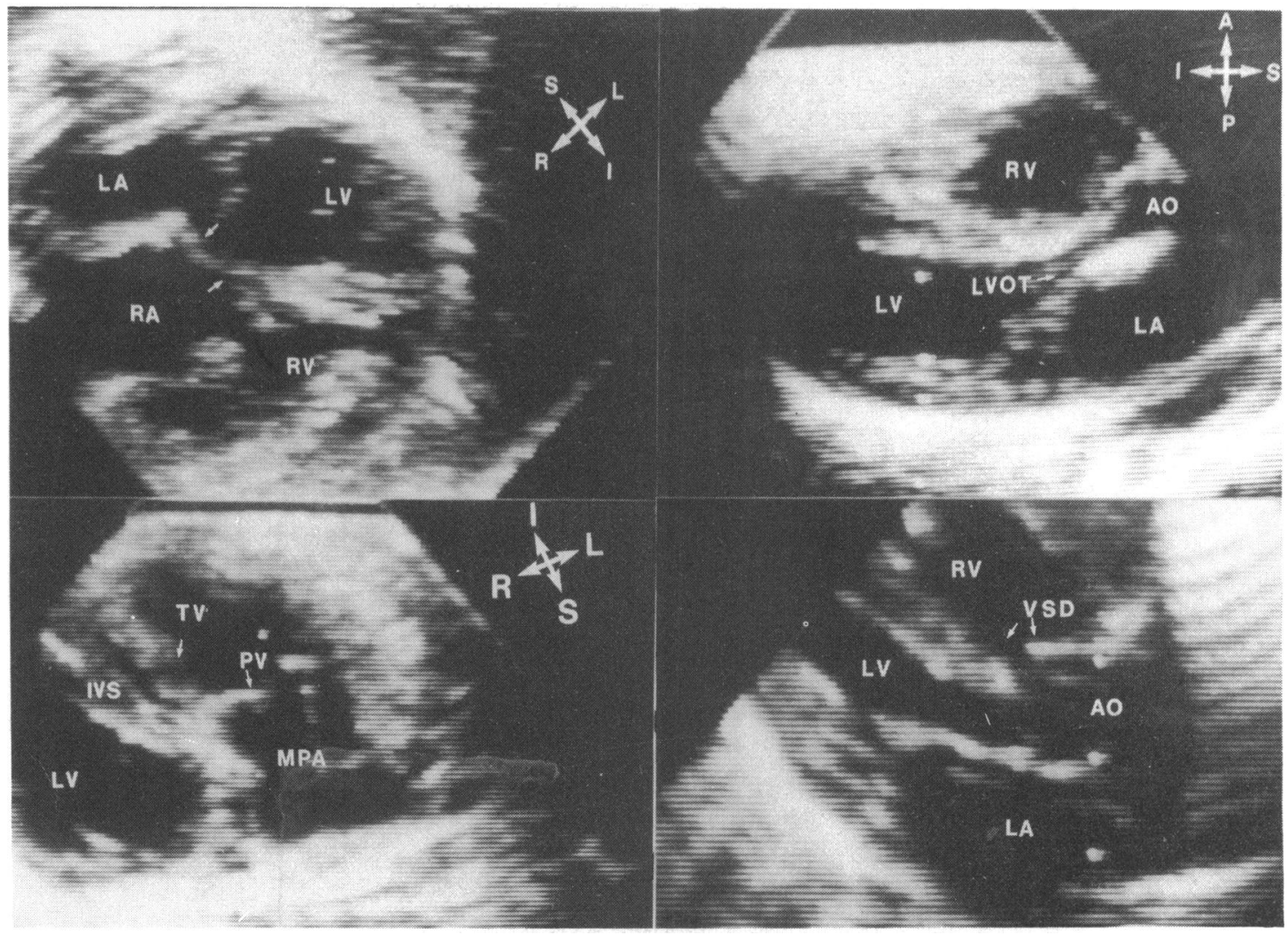

Fig. 3 The upper left picture is a subcostal four chamber cut in coarctation of the aorta and perimembranous trabecular ventricular septal defect. Note that the atrioventricular valves are offset, indicating an intact muscular atrioventricular septum. The upper right picture is a precordial long axis cut from the same case demonstrating a narrow left ventricular outflow tract. The lower left picture is a precordial long axis cut with clockwise rotation showing the tricuspid valve inserting just beneath the pulmonary valve. Note the infundibular septum is normally positioned. The lower right picture is a precordial long axis cut showing the ventricular septal defect and overriding of the aortic valve. LVOT, left ventricular outflow tract; MPA, main pulmonary artery; $R A$, right atrium. For rest of abbreviations see Fig. 1 and 2.

defect. Aortic override was present in all cases, with the left ventricular outflow tract appearing narrow in three. In the other four cases the defect was perimembranous and extended into the inlet, trabecular, and outlet septum (Fig. 4). Aortic override was present in all cases and the left ventricular outflow tract appeared narrow in one (Fig. 4).

In no cases did the mitral valve obstruct the left ventricular outflow tract. Similarly there was also no evidence of a subaortic ridge. In nine cases with a perimembranous defect and one with a muscular trabecular defect, the tricuspid valve was inserted abnormally high into the infundibular septum (Fig. 3). The medial papillary muscle was also situated more anteriorly in the trabecular septum (Fig. 5). The result of this was that in the precordial long axis cut at right angles to the outlet septum and the four chamber aortic root cut the defect appeared to be obscured by the tricuspid valve (Fig. 5). In four cases the tricuspid valve tissue entered the left ventricular outflow tract through the ventricular septal defect during systole (Fig. 4 and 5). This appearance could be seen both in the precordial short axis cut as the transducer was scanned towards the left ventricular outflow tract (Fig. 6) and in the precordial long axis cut. Necropsy confirmation of the defect was available in one case with a perimembranous trabecular ventricular septal defect (Fig. 7). 


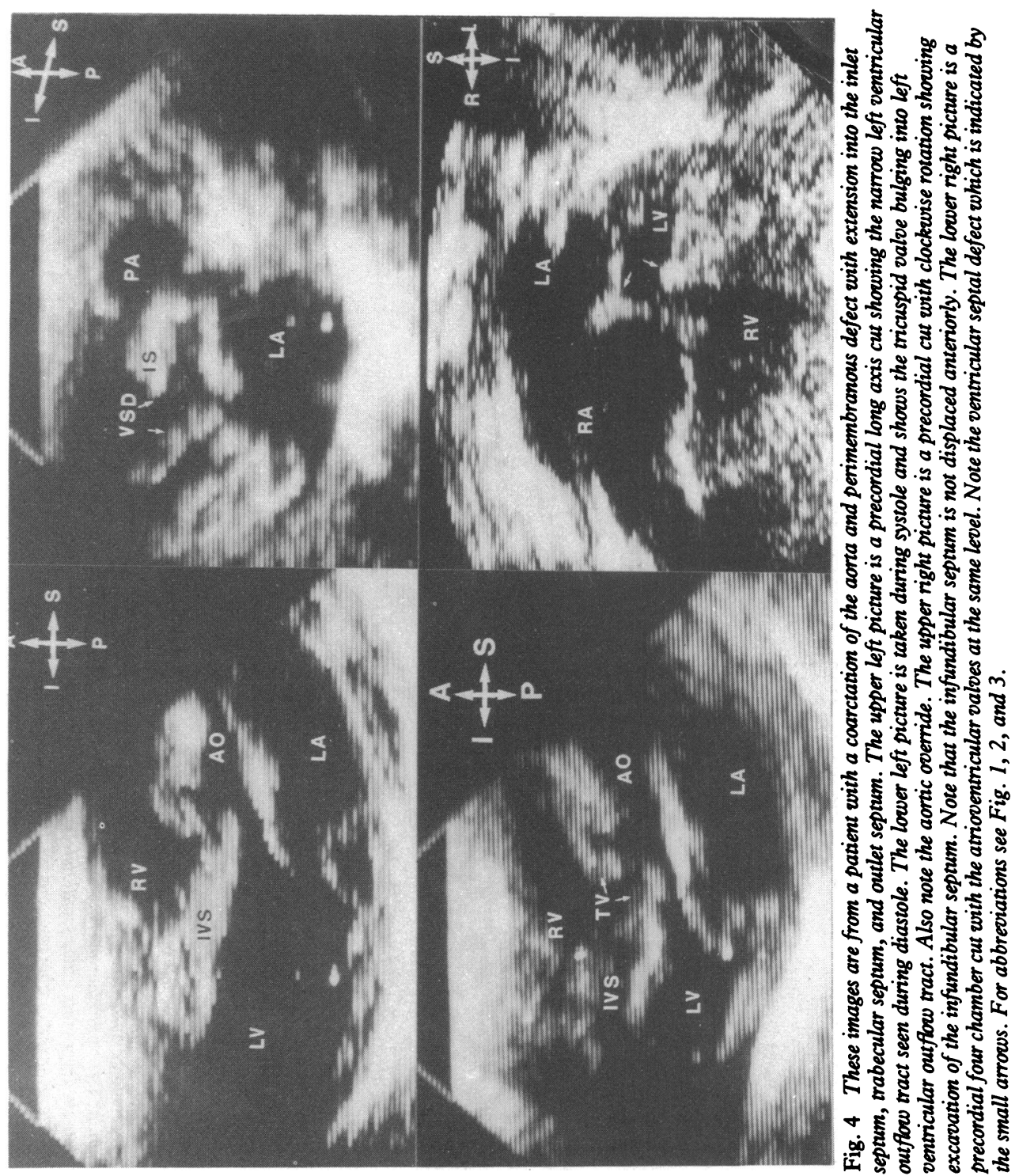



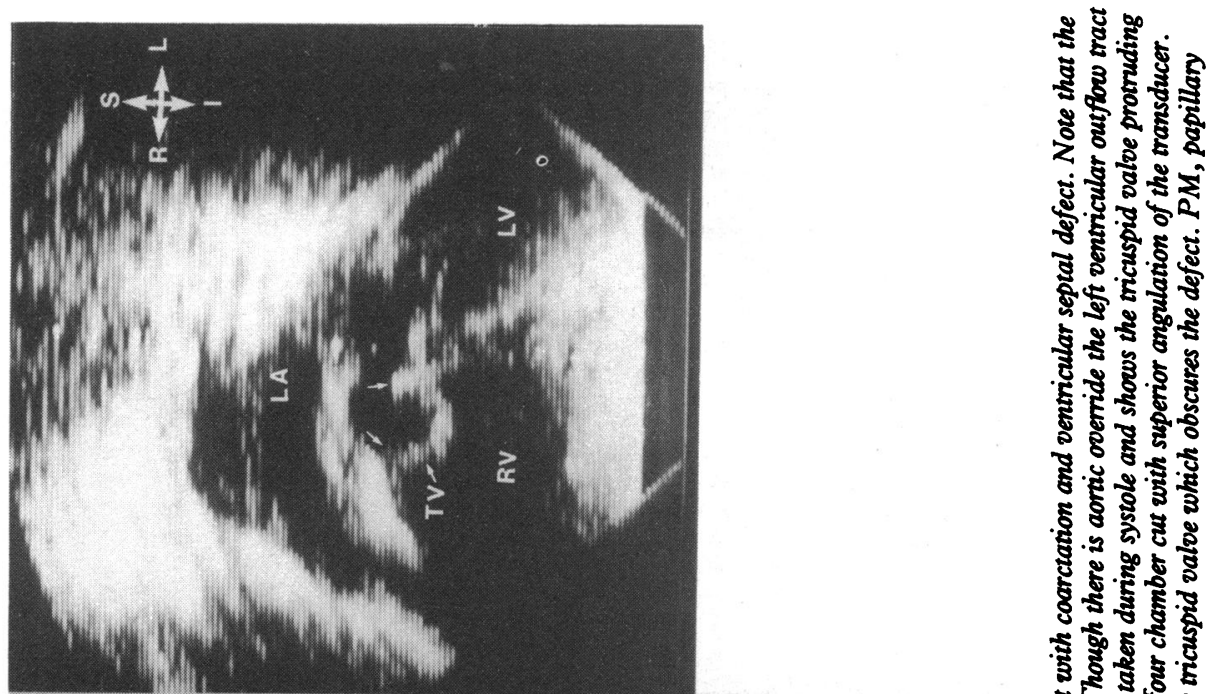

ปั

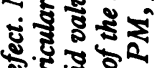

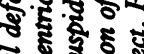

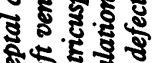

बृ. है

हैं

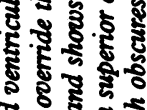

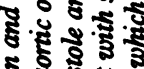

ริ

ํำ

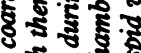

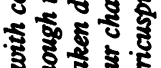

है.

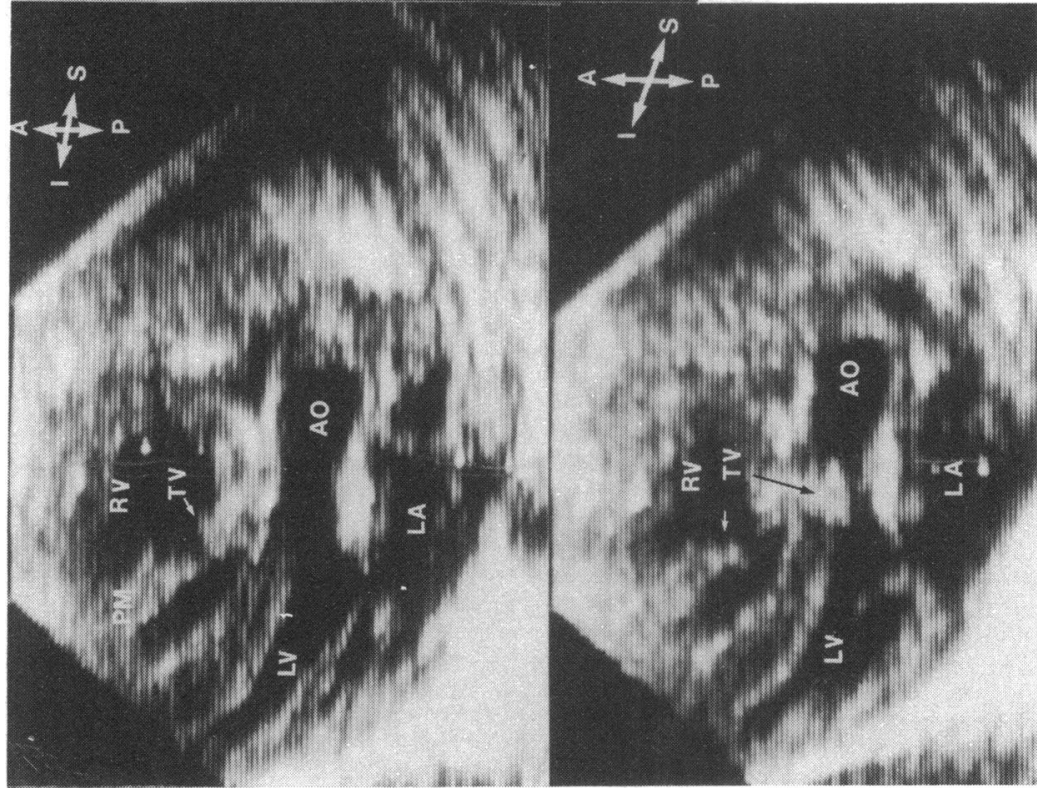

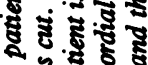

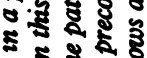

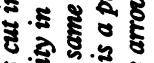

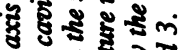

०ूड है है है है

ड टैं

है

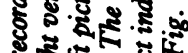

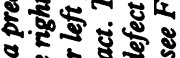

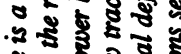

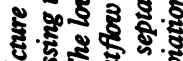

हू हैं है

ริ

4 .

ริ

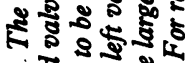

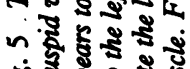

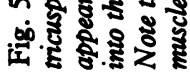




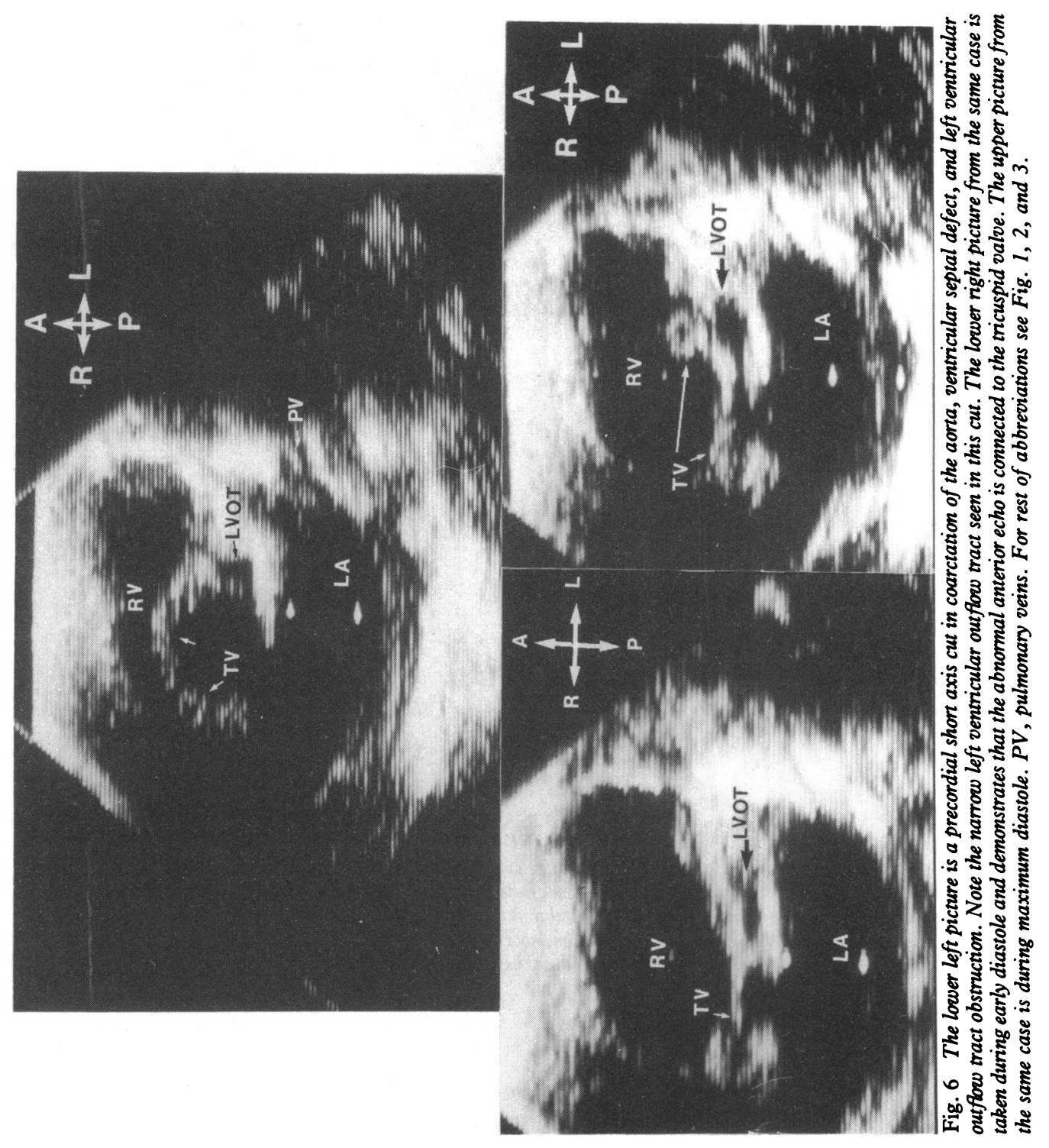



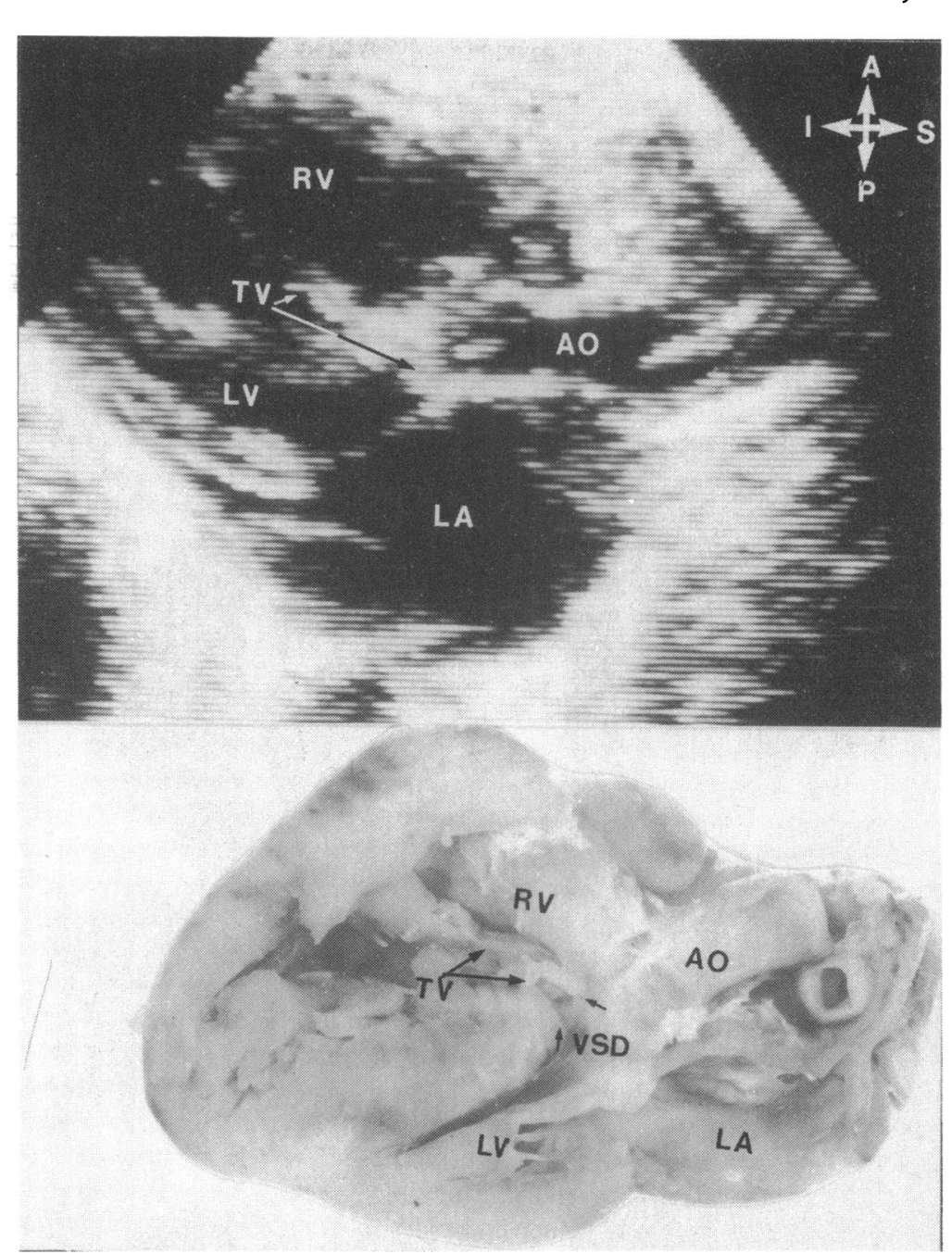

Fig. 7 The upper picture is a precordial long axis cut in coarctation of the aorta, ventricular septal defect, and abnormal insertion of the tricuspid valve. Note during systole the tricuspid valve protrudes into the left ventricular outflow tract. The tricuspid valve tissue obscures the ventricular septal defect. In addition, note the aortic override. The lower picture is a specimen from the same patient cut to simulate the echocardiographic appearance. For abbreviations see Fig. 1 and 3.

\section{Discussion}

Cross-sectional echocardiography has proved to be a reliable method for both identifying and accurately locating the position of a ventricular septal defect, provided the defect falls within the range of axial and lateral resolution of the equipment. ${ }^{78}$ Visualisation of the left ventricular outflow tract is readily achieved by the above technique, which, in the presence of an adjacent ventricular septal defect, frequently showed severe narrowing in the absence of a demonstrable pressure gradient at the site. ${ }^{1}$

The range of defects seen in this series differs slightly from that reported after anatomical examination of the necropsy population of The Children's Hospital of Pittsburgh. ${ }^{6}$ It is likely that these findings represent a truer spectrum of the frequency seen in clinical practice of the types of ventricular septal defect associated with aortic coarctation. In the necropsy study ${ }^{6}$ four cases had a muscular outlet defect 


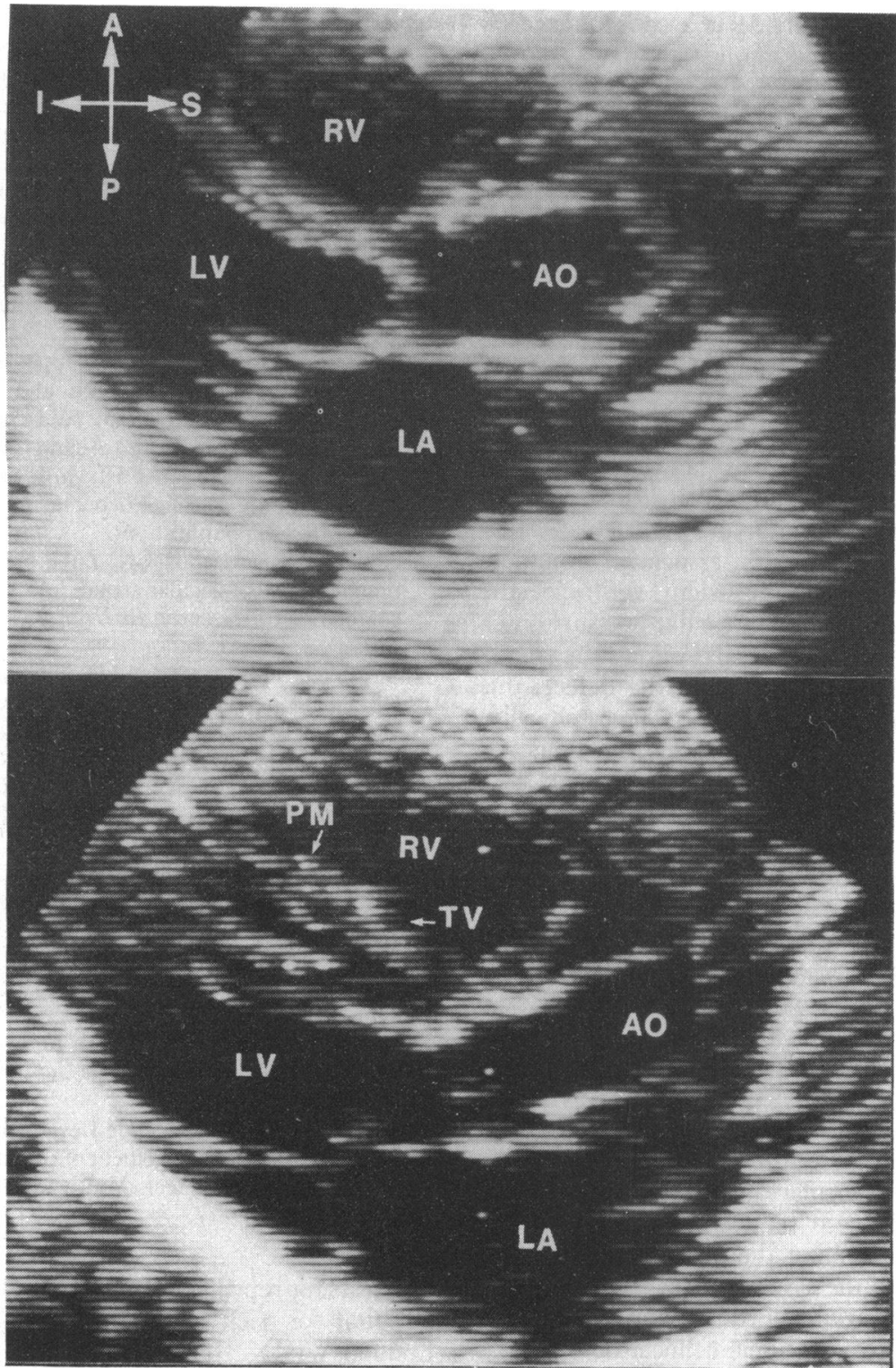

Fig. 8 The upper picture is a precordial long axis cut in coarctation of the aorta without a ventricular septal defect. Note that the aortic root appears to override the interventricular septum, despite the lack of ventricular component. The lower picture is also from a patient with coarctation and intact ventricular septum. Note that the tricuspid valve is inserted abnormally. For abbreviations see Fig. 1, 3, and 5.

associated with posterior displacement of the outlet septum, while 20 out of the remaining 21 had a large perimembranous defect with extension into all components of the septum together with associated aortic override.

Even so, in this clinical series aortic override associ- ated with a large perimembranous defect was seen in 10 cases (58\%), while left ventricular outflow tract narrowing caused by posterior displacement of the outlet septum was seen in five (28\%). In all cases with aortic override the outlet septum was normally positioned (Fig. 3 and 4), unlike patients with Fallot's 
tetralogy in whom the override is a consequence of anterior displacement of the outlet septum.

The abnormal insertion of the tricuspid valve, such that it crosses the ventricular septal defect before inserting into the underside of the outlet septum provides a pocket of tissue which obscures the defect. This feature was also noted in the necropsy series. ${ }^{6}$ The appearance of the tricuspid leaflet tissue crossing the place of the transducer in the long axis has only in our experience been seen previously in patients with double outlet right ventricle and subpulmonary ventricular septal defect, or complete transposition associated with a ventricular septal defect. ${ }^{910}$

Right ventricular hypertension is common in infants with coarctation of the aorta even when there is no ventricular septal defect or a small one. ${ }^{11}$ Thus in many cases with coarctation and ventricular septal defect, and in all cases with associated complete transposition or double outlet right ventricle, the combination of a high right ventricular pressure and a high insertion of the tricuspid valve allows the tricuspid tissue tag to be forced through the defect, this being readily demonstrable echocardiographically. Whether this tissue eventually closes the defect is open to speculation and can only be determined by a prospective study. Interestingly, similar tricuspid valve anatomy (Fig. 7) was seen in some patients presenting to our institution with a diagnosis of coarctation of the aorta but with an intact ventricular septum. Aortic override was also observed in some of these patients and it was evident that a pre-existing ventricular septal defect had been completely closed either in utero or during the first weeks of life (Fig. 8). Thus, as in the necropsy series, the most common type of ventricular septal defect seen in aortic coarctation in patients who survive the critical period of early infancy is one whose morphology, in combination with that of the ventricular outflow tracts, might be expected significantly to reduce the amount of left ventricular blood reaching the aortic isthmus. This entire complex, and the association of tricuspid valve abnormalities in those with aortic override, are readily demonstrated by cross-sectional echocardiography.

\section{References}

1 Smallhorn JF, Anderson RH, Macartney FJ. Crosssectional echocardiographic recognition of interruption of aortic arch between left carotid and subclavian arteries. Br Heart $\mathcal{F}$ 1982; 48: 229-35.

2 Van Praagh R, Bernhard WF, Rosenthal A, Parisi LF, Fyler DC. Interrupted aortic arch: surgical treatment. Am f Cardiol 1971; 27: 200-11.

3 Freedom RM, Bain HH, Esplugas E, Dische R, Rowe RD. Ventricular septal defect in interruption of aortic arch. Am f Cardiol 1977; 39: 572-82.

4 Moulaert AJ, Bruins CC, Oppenheimer-Dekker A. Anomalies of the aortic arch and ventricular septal defects. Circulation 1976; 53: 1011-5.

5 Smallhorn JF, Huhta JC, Adams PA, Anderson RH, Wilkinson JL, Macartney FJ. Cross-sectional assessment of coarctation in the sick neonate and infant. Br Heart $\mathcal{F}$ (submitted for publication).

6 Anderson RH, Lenox CC, Zuberbuhler JR. The morphology of a ventricular septal defect in association with coarctation of the aorta. Br Heart $\mathcal{F}$ (submitted for publication).

7 Sutherland GR, Godman MJ, Smallhorn JF, Guiterras P, Anderson RH, Hunter S. Ventricular septal defects. Two-dimensional èchocardiographic and morphological correlations. Br Heart $\mathcal{F}$ 1982; 47: 316-28.

8 Bierman FZ, Fellows K, Williams RG. Prospective identification of ventricular septal defects in infancy using subxiphoid two-dimensional echocardiography. Circulation 1980; 62: 807-17.

9 Huhta JC, Edwards WD, Danielson GK, Feldt RH. Abnormalities of the tricuspid valve in complete transposition of the great arteries with ventricular septal defect. F Thorac Cardiovasc Surg 1982; 83: 569-76.

10 Huhta JC, Smallhorn JF, de Leval MR, Macartney FJ. Tricuspid valve abnormalities in DORV with subpulmonic VSD [Letter]. $\mathcal{F}$ Thorac Cardiovasc Surg 1982; 84: 154-5.

11 Leanage R, Taylor JFN, de Leval MR, Stark J, Macartney FJ. Surgical management of coarctation of aorta with ventricular septal defect. Multivariate analysis. $\mathrm{Br}$ Heart f 1981; 46: 269-77.

Requests for reprints to Professor F J Macartney, The Hospital for Sick Children, Great Ormond Street, London WC1N 3JH. 